\section{Maternal administration of flecainide to terminate and suppress fetal tachycardia}

Fetal echocardiography has allowed fetal arrhythmias to be identified and accurately diagnosed. Because a fetal tachycardia is often detected before an elective delivery is safe considerable interest has focused on treatment by giving drugs to the mother. Digoxin is accepted as the drug of first choice, but no consensus exists on second line drugs. ${ }^{12}$ We present the first report of giving flecainide to a mother to terminate and suppress a fetal tachycardia.

\section{Case report}

A tachycardia was identified during routine auscultation of the fetal heart at 28 weeks' gestation. The echocardiogram showed a ventricular rate of 240 beats $/ \mathrm{min}$ with a $1: 1$ atrioventricular relation. The tachycardia was present $95 \%$ of the time. The heart was structurally normal, but a moderate pericardial effusion and ascites were noted.

The mother was given oral digoxin $500 \mu \mathrm{g}$ three times in 24 hours and then $500 \mu \mathrm{g}$ daily, which resulted in a trough plasma concentration of $1.5 \mu \mathrm{g} / \mathrm{l}$. Repeat echocardiography over the next 11 days showed persistent tachycardia with no change in the pericardial or ascitic effusions.

At 30 weeks' gestation the mother was admitted to hospital. Three echocardiograms taken on the day of admission confirmed a tachycardia. During echocardiographic monitoring of the fetus the mother was given intravenous flecainide $110 \mathrm{mg}(1.4 \mathrm{mg} / \mathrm{kg})$ over five minutes. The fetal ventricular rate slowed from 235 to 214 beats/min and then fell abruptly to 120 beats/min as the tachycardia stopped and sinus rhythm supervened (figure). Sinus rhythm persisted during observation for the next 10 minutes. Oral flecainide $100 \mathrm{mg}$ three times daily was substituted for the digoxin treatment. The fetus remained in sinus rhythm, and the maternal echocardiogram did not change. Echocardiograms taken on four subsequent occasions showed no recurrence of the arrhythmia. All traces of pericardial and ascitic effusion resolved within 10 days. The maternal plasma concentration of flecainide measured once before administration of the drug was $656 \mu \mathrm{g} / \mathrm{l}$ (normal adult therapeutic range $400-1000 \mu \mathrm{g} / \mathrm{l}$ ).

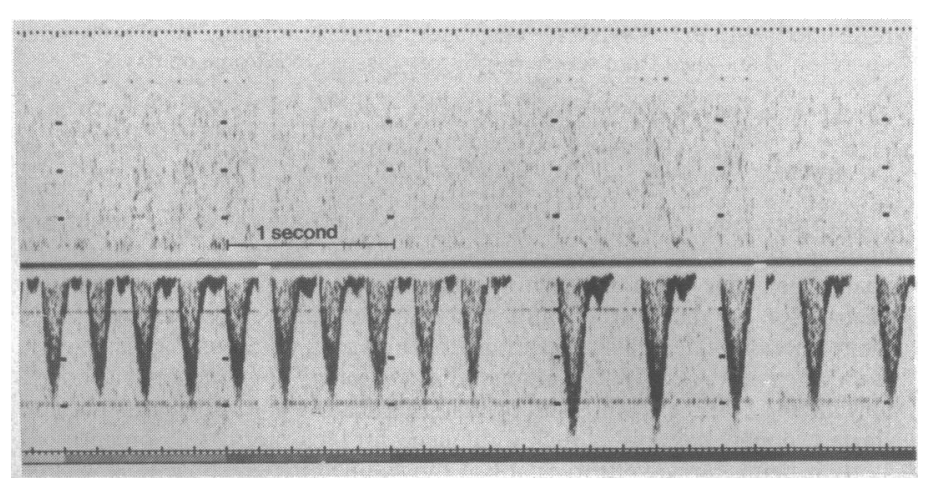

Pulsed Doppler recording of blood velocity in fetal ascending aorta during intravenous administration of flecainide to the mother.

Labour was induced at 38 weeks' gestation, and a female baby weighing $3450 \mathrm{~g}$ was delivered in good condition. A 12 lead electrocardiogram showed no evidence of pre-excitation. The baby did not receive any drugs, and arrhythmia did not recur during observation for 10 days. Concentrations of flecainide in maternal and cord plasma obtained simultaneously five hours after the last oral dose were 833 and $533 \mu \mathrm{g} / \mathrm{l}$, respectively.

\section{Comment}

Assessment of the effectiveness of treatment of fetal arrhythmias is hampered by lack of knowledge of the natural course of these conditions and the transplacental pharmacokinetics of many drugs and their modification by fetal hydrops. Termination of a fetal tachycardia some days after the start of oral treatment of the mother may be spontaneous rather than drug induced. ${ }^{\prime}$

Digoxin is accepted as the drug of first choice for treating fetal tachycardia ${ }^{12}$ but is ineffective in up to half of cases. ${ }^{1}$ Reports of treatment with other drugs are few, but tachycardia has been terminated with propranolol, verapamil, procainamide, and amiodarone. ${ }^{12}$ Verapamil is not recommended for neonatal tachycardia, and its use in fetal hydrops may be associated with fetal or neonatal death.
Flecainide was chosen in this case because it is known to be safe and effective in various types of arrhythmias in children. ${ }^{3}$ Although its transplacental pharmacokinetics are not known, its molecular weight (474.4 daltons) suggests that it should cross the placenta easily. ${ }^{4}$ The rapid termination of the tachycardia confirmed its efficacy and justified oral administration to the mother to prevent recurrence. Further experience is needed, however, to compare flecainide with other drugs before it can be recommended for treating fetal tachycardia.

We thank Professor T Lind for cooperation in the management of the patient.

1 Wladimiroff JW, Stewart PA. Treatment of fetal cardiac arrhythmias. Br f Hosp Med 1985;34: 134-40.

2 Kleinman CS, Copel JA, Weinstein EM, Santulli TV Jr, Hobbins JC. In utero diagnosis and treatment of fetal supraventricular tachycardia. Semin Perinatol 1985;9:113-29.

3 Wren C, Campbell RWF. The response of paediatric arrhythmias to intravenous and oral flecainide. Br Heart f 1987;57:171-5.

4 Finster M, Pedersen H. Placental transfer and fetal uptake of drugs. Br $\mathcal{f}$ Anaesth 1979;51(suppl): $25-28 \mathrm{~S}$

(Accepted 21 September 1987)

Department of Paediatric Cardiology, Freeman Hospital, Newcastle upon Tyne NE7 7DN

CHRISTOPHER WREN, MRCP, senior registrar

STEWART HUNTER, FRCP, consultant

Correspondence to: Dr Wren.

\section{High dose intravenous methylprednisolone or high dose intravenous gammaglobulin for autoimmune thrombocytopenia}

Since the initial report of Imbach et al high dose intravenous gammaglobulin has become a popular treatment for autoimmune thrombocytopenia. ${ }^{1}$ It is effective, induces a quick rise in the platelet count, and rapidly diminishes bleeding; moreover, it has no appreciable side effects. ${ }^{23}$ It seems to be the treatment of choice in patients with an active bleeding tendency ("wet purpura"), but it is expensive.

Intravenous gammaglobulin probably works by transient inhibition of autoantibody mediated platelet destruction by the cells of the macrophage system (at the level of IgG Fc receptors), although other mechanisms have been postulated as well. ${ }^{2}$ Glucocorticosteroids also inhibit the destruction of autoantibody sensitised platelets by the cells of the macrophage system. ${ }^{4}$ From experience with the treatment of organ graft rejection high doses of intravenous corticosteroids are also known to be rapidly effective. When given only for a few days they have no serious side effects, and are not so expensive as gammaglobulin. Hence we studied the effect of high dose intravenous methylprednisolone in treating patients with autoimmune thrombocytopenia, comparing it with intravenous gammaglobulin and oral prednisolone.

\section{Patients, methods, and results}

The patients were adults with their first attack of idiopathic autoimmune thrombocytopenia. Some were treated again for a relapse, after having no treatment (oral prednisolone) for over three months. Bone marrow appearances were normal, with a normal or increased number of megakaryocytes and a positive immunofluorescence test for platelet autoantibodies. Other causes for thrombocytopenia were excluded. Ten patients were treated with one course of intravenous methylprednisolone $(1000 \mathrm{mg})$ given over half an hour for three consecutive days. Twelve other patients were treated once and two twice with intravenous gammaglobulin (from the Central Laboratory of the Netherlands Red Cross Blood Transfusion Service $\left.{ }^{5}\right) 0.4 \mathrm{~g} / \mathrm{kg}$ for five days. A dose of $20 \mathrm{mg}$ prednisolone was started after this initial treatment. Platelet counts were determined daily or every other day by standard methods. Of a control series of 17 patients 14 were treated once and three twice with oral prednisolone, $40-80 \mathrm{mg}$ daily, given in three to four doses per day.

Intravenous methylprednisolone was as effective as intravenous gammaglobulin in terms of the frequency of response. The proportion of patients who obtained an adequate platelet count $\left(>50 \times 10^{9} / 1\right)$ within 10 days was $80 \%$ ( 8 out of 